\title{
Influence of noun imagery on speed of naming nouns
}

\author{
DAVID A. GRANT, JEFFREY A. KADLAC, and MICHAEL J. ZAJANO \\ University of Wisconsin, Madison, Wisconsin 53706 \\ JOSEPH B. HELLIGE \\ University of Southern California, Los Angeles, California 90007 \\ LOUISE C. PERRY \\ University of Queensland, St. Lucia, Queensland 4067 Australia
}

and

\author{
KENNETH B. SOLBERG \\ St. Mary's College, Winona, Minnesota 55987
}

\begin{abstract}
In an experiment on the influence of noun imagery on the speed of naming visually presented nouns, it was found that high-imagery nouns were named, on an average, $14 \mathrm{msec}$ faster than low-imagery nouns. The difference, although small, was highly significant $[F(1,14)=10.04]$. The magnitude of this effect was about one-third of that obtained when subjects were required to identify the grammaticality of phrases containing these same nouns, indicating that speed of encoding was probably a more important factor than speed of recognition in producing a noun imagery effect in speed of grammaticality judgments.
\end{abstract}

The purpose of the experiment here reported was to investigate the role of rated noun imagery in the speed of noun recognition as measured in a noun naming task.

In a previous experiment on differential eyelid conditioning (Perry, Grant, \& Schwartz, in press), the differential stimulus was the grammaticality of adjectivenoun phrases. The adjective was always "One" or "Two" followed by a singular or plural noun. A singular adjective followed by a singular noun (SS) and a plural adjective followed by a plural noun (PP) were grammatically correct phrases. A singular adjective followed by a plural noun (SP) and a plural adjective followed by a singular noun (PS) were grammatically incorrect. The basic finding was that grammaticality was a more effective discriminative stimulus when the phrases contained high-imagery nouns than when they contained lowimagery nouns. In a subsequent experiment on speeded grammaticality judgments, Grant, Kadlac, Schwartz, Zajano, Hellige, Perry, and Solberg (in press) showed that correct grammar, singular noun form, high noun imagery, and reported use of an artificial strategy in which the subject read the adjective and skipped immediately to see if the noun ended with an "s," all produced highly significant reductions in reaction time. Only $1 \%$ of the interactions were significant at the $5 \%$ level, so a multistage serial processing model based upon Sternberg's additive factor method was found to be highly successful in describing the results. Thus, the imagery level of the nouns in adjective phrases was shown to influence behavior in a differential eyelid conditioning experiment where the subjects were in a state of relatively low arousal due to a neutral instructional set, and in a reaction time experiment, where the subjects were in a state of relatively high arousal due to instructions to identify as quickly as possible whether or not the phrase was grammatically correct. One possible way in which noun imagery could affect the speed of processing the adjective-noun phrases would be the relative speed of recognizing the highand low-imagery nouns. For example, Atkinson and Juola (1973) found that concrete nouns were recognized more quickly than abstract nouns, but their report does not make clear the degree to which their word sets were matched on other variables, so we cannot treat their findings unequivocally.

\section{METHOD}

\section{Apparatus}

The subject sat in a double soundproofed chamber approximately $170 \mathrm{~cm}$ from a ground-glass screen which was located at the rear of a white rectangular enclosure $85 \times 65 \times 88 \mathrm{~cm}$ deep. Communication with the subject during the experiment was by intercom, and the instructions to the subject were given by means of a tape recorder located inside the chamber. The instructions stated that the subjects were to be tested on how quickly and accurately they could pronounce words that would be flashed on the screen before them and that they would hear a .5 -sec warning tone before each word appeared. The onset of the tone preceded the word by $1.5 \mathrm{sec}$, and the time between stimulus onsets was $12 \mathrm{sec}$. The stimuli were back-projected onto the center of the screen by means of a Kodak Ektographic slide 
projector. A digital clock recorded to the nearest millisecond the recognition times, which were picked up by a small microphone about $10 \mathrm{~cm}$ in front of the subject's chin.

\section{Stimulus Materials}

The stimuli consisted of the same 80 high-imagery and 80 low-imagery nouns that had been used in Experiment 2 by Perry, Grant, and Schwartz (in press). These nouns had been selected from the Paivio, Yuille, and Madigan norms (1968). For the high-imagery set the average imagery rating, concreteness ratings, and familiarity $(\mathrm{M})$ were $6.32,6.58$, and 6.49 , respectively. The corresponding averages for the low-imagery set were $3.27,3.18$, and 5.21 . In addition to these 160 nouns, there was a set of 24 practice nouns whose imagery ratings averaged 4.75 . None of these nouns were used in the experiment proper. The nouns had been photographed on highcontrast film and overexposed so that on the negatives, used as stimuli, the phrases appeared white on a very dark background. The projected size of the stimuli was $1.11 \mathrm{~cm}$ in height (visual angle, $.59 \mathrm{deg}$ ) for the initial capital letters and $.8 \mathrm{~cm}$ or $.43 \mathrm{deg}$ for small letters. The length of the noun varied from about $4 \mathrm{~cm}(2.14 \mathrm{deg})$ to about $12 \mathrm{~cm}(6.40 \mathrm{deg})$.

\section{Subjects}

Eight men and eight women students from introductory psychology courses served as subjects. English was the native language of all of the subjects, and they had been screened for normal vision before the experiment.

\section{Procedure}

After the 24 practice trials, each subject was presented two sets of 80 nouns each. Each set was arranged in blocks of eight trials, with four high imagery and four low in each block. A short rest period was given between sets, and the order of the two sets was counterbalanced across subjects.

\section{RESULTS AND DISCUSSION}

Median response times were obtained for the highand low-imagery nouns, and these medians were analyzed for imagery, sex of subject, word set, and order of presentation of these sets. The only statistically significant main effect was that of imagery, the main response times to high-imagery nouns being $585 \mathrm{msec}$ compared to $599 \mathrm{msec}$ for low-imagery nouns $[\mathrm{F}(1,14)=$ $10.04, \mathrm{p}<.01, \mathrm{MSe}=350]$. The 14-msec difference in speed of naming high-imagery nouns compared to low-imagery nouns is less than one-third of the 48-msec difference in identifying the grammaticality of phrases containing the high-imagery nouns (Grant et al., in press). Therefore, it appears that differences in speed of noun recognition and speed of noun encoding may both be involved in the imagery effect on speed of processing grammaticality, but that speed of encoding appears to be the major factor.

\section{REFERENCES}

Atkinson, R. C., \& JuolA, A. F. Factors influencing speed and accuracy of word recognition. In S. Kornblum (Ed.), Attention and performance IV. New York: Academic Press, 1973.

Grant, D. A., Kadlac, J. A., Schwartz, M., Zajano, M. J., Hellige, J. B., Perry, L. C., \& Solberg, K. B. The role of noun imagery in the speed of processing the grammaticality of adjective-noun phrases. Memory \& Cognition, in press.

Paivio, A., Yuille, J. C., \& Madigan, S. A. Concreteness, imagery, and meaningfulness values for 1925 nouns. Journal of Experimental Psychology, Monograph Supplement, 1968, 76(Part 2), 1-25.

Perry, L. C., Grant, D. A., \& Schwartz, M. Grammaticality of high- and low-imagery noun phrases as the cue in differential eyelid conditioning. Memory \& Cognition, in press.

Received for publication January 21, 1977.) 